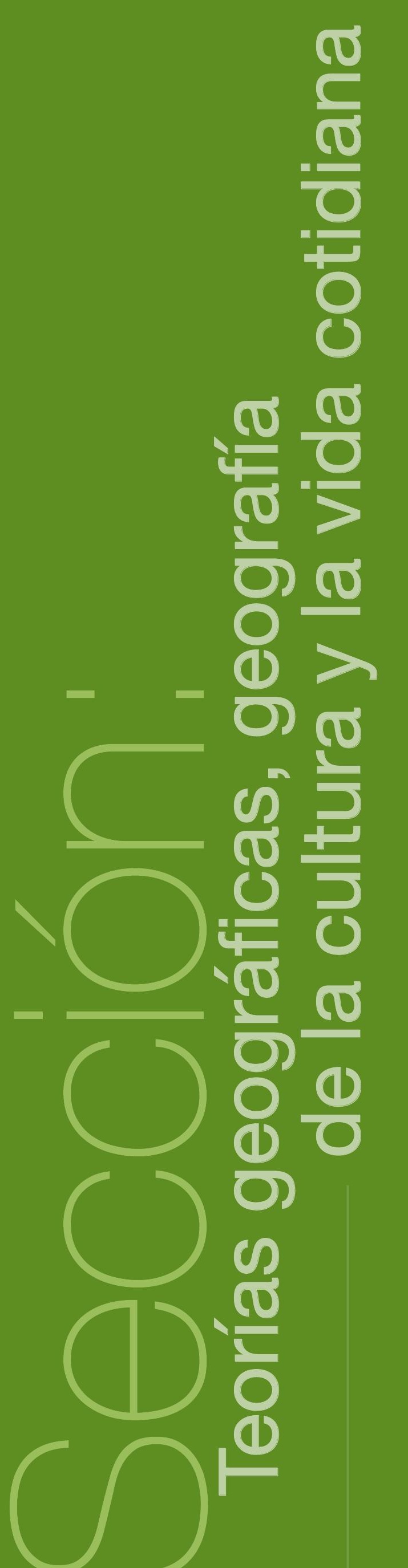




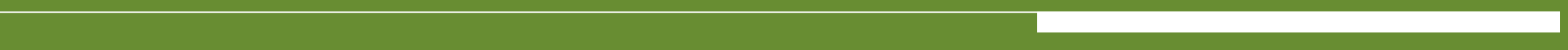

SECCIÓN: Teorías geográficas, geografía de la

cultura y la vida cotidiana
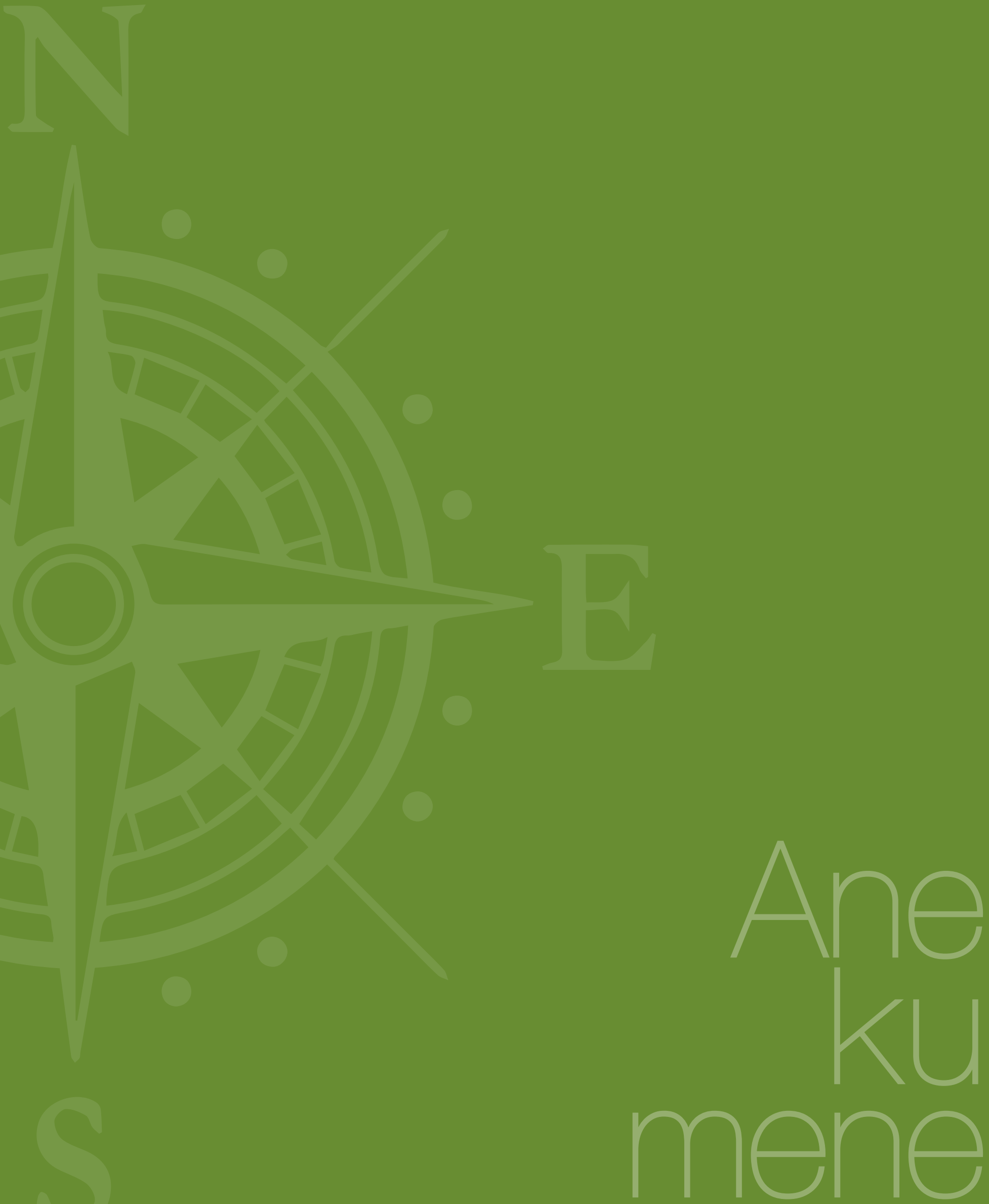


\title{
El tercer espacio en la experiencia juvenil callejera: Desafío para la imaginación geográfica
}

\section{O terceiro espaço na experiência de jovens nas ruas: Desafio para a imaginação geográfica The Third Space in Youngsters' Street Experience: A Challenge for Geographic Imagination}

\author{
Sandra Martínez Murillo
}

\section{Resumen}

Este artículo presenta elementos conceptuales que se tejen entre el habitar, la experiencia y el tercer espacio en el escenario callejero del centro de la ciudad de Bogotá, a partir del proceso investigativo ${ }^{1}$ sobre la configuración del espacio desde las experiencias del grupo de jóvenes Inframundos Underground ${ }^{2}$ en "El Cartucho" ${ }^{3}$ y en el barrio San Bernardo; un sector de la ciudad donde espacial, social e históricamente se han arraigado situaciones de violencia e ilegalidad. Dicha interrelación conceptual aporta a los estudios socioespaciales, por cuanto es pertinente para profundizar en la relación entre juventudes y el espacio urbano.

\section{Palabras clave}

habitar; experiencia;

tercer espacio;

jóvenes callejeros

1 El trabajo se titula: Miradas callejeras de ciudad. Experiencias juveniles desde El Cartucho y el San Bernardo, para optar por el título de Maestría en Estudios Sociales de la Universidad Pedagógica Nacional. Línea de investigación Construcción Social del Espacio-Grupo de investigación Geopaideia.

2 Nombre con el cual se hacen llamar los jóvenes como grupo ("parche").

3 Zona de expendio y consumo de sustancias ilegales ubicada en el antiguo barrio Santa Inés en la ciudad de Bogotá, que fue demolido como parte del proceso de renovación urbana en el centro de la ciudad. 


\section{Resumo}

\section{Palavras chave}

habitar; experiência; terceiro espaço; jóvens da rua

\section{Keywords \\ living; experience; third space; street youngsters}

Este artigo apresenta elementos conceptuáis tecidos entre o habitar, a experiência e o terceiro espaço no cenário da rua no centro da cidade de Bogotá, a partir do processo investigação sobre a configuração do espaço desde as experiências do grupo de jóvens Inframundos Underground em "El Cartucho" e no bairro "San Bernardo": uma zona da cidade onde espacial, social e historicamente se têm fixado situações de violencia e ilegalidade. Essa inter-relação conceptual contribui aos estudos socio-espaciáis enquanto é pertinente para aprofundar na relação entre jóvens e o espaço urbano".

\section{Abstract}

This paper presents concept elements that are woven between the living, experience and the third space in the street scenario of downtown Bogota, from a research on the configuration of space from experiences of the Inframundos Underground young group in "El Cartucho" and in the San Bernardo neighborhood. Situations of violence and illegality have rooted spatially, socially and historically in this area of the city. This concept interrelation contributes to social and spatial studies, as it is relevant to deepen the relationship between youth and urban space. 


\section{Presentación}

Bogotá, al igual que varias ciudades latinoamericanas, ha presentado un acelerado proceso de crecimiento durante las últimas seis décadas en términos demográficos y económicos. Ello ha implicado, entre otros aspectos, albergar a gran parte de la población colombiana, situación que se entiende en el marco del conflicto armado y sus consecuencias sobre los desplazamientos a la capital del país. La urbanización, en ciudades como Bogotá, São Paulo y Ciudad de México, en cierta medida concentra espacialmente la pobreza y las diferencias socioeconómicas, así como la agudización de los conflictos sociales expresados, por ejemplo, en las violencias urbanas. En ese contexto de ciudad, el centro ha sido un escenario clave en las transformaciones que han constituido el proceso de crecimiento urbano. El año de 1948 marca un hito para Bogotá y sus habitantes, pues no solo comienzan a cambiar las formas de habitar el centro, sino que además este se convierte paulatinamente en lugar de recepción de muchos colombianos que huyen de la violencia desplegada en sus territorios de origen hacia la capital.

Para la investigación en referencia cobra un sentido importante la zona céntrica comprendida por los barrios Santa Inés y San Bernardo, principalmente, los cuales se encuentran entre los más antiguos de Bogotá y han sido vinculados a procesos de renovación urbana dadas las condiciones de violencia y deterioro que allí se han producido. El Santa Inés extinto y reemplazado por lo que hoy se conoce en la ciudad como el parque Tercer Milenio ${ }^{4}$, y el San Bernardo ${ }^{5}$, barrio vecino, que forma parte del proyecto "Ciudad salud" ${ }^{6}$, han comenzado a ser intervenidos recientemente.

4 De acuerdo al Decreto 346 de 2003, por el cual se adopta "el plan maestro del parque Tercer Milenio", con las siguientes consideraciones:

- Que el Decreto 462 del 7 de mayo de 1998 asignó tratamiento de Renovación Urbana al sector comprendido por los barrios Santa Inés y San Bernardo del centro de Bogotá

- Que el Decreto 880 de 1998 adoptó el programa de Renovación Urbana para la recuperación del sector comprendido entre los barrios San Bernardo y Santa Inés y su área de influencia, en el cual se incluye el parque Tercer Milenio como componente del espacio público.

- Que el artículo 3. ${ }^{\circ}$ del Decreto 880 de 1998 estableció entre los objetivos y políticas del programa de Renovación Urbana, crear el parque Tercer Milenio para consolidar y estructurar los espacios públicos de la ciudad y permitir el soporte de nuevas densidades y usos del sector

- Que con la construcción del parque Tercer Milenio se pretende aumentar la cantidad y calidad de los espacios públicos recreativos y mejorar las condiciones ambientales y de habitabilidad para atraer el uso residencial en el centro de la ciudad.

5 También referenciado como barrio Liévano.

6 Para el Nodo Centro se encuentran en etapa de formulación los planes parciales de renovación de San Victorino, San Bernardo y 'Ciudad Salud', que esperan completar el desarrollo urbanístico de la zona comprendida entre la avenida Jiménez y la calle Primera al sur y la carrera Décima y la avenida Caracas. Esta actuación es estratégica dada la localización de importantes equipamientos de la ciudad como son el parque Tercer Milenio y el grupo de ocho hospitales alrededor del Hospital San Juan de Dios, la Plaza de la Mariposa, las troncales de transporte masivo de la carrera décima y la avenida Caracas y el futuro intercambiador de la carrera décima con calle sexta.
La historia de estos barrios ha estado configurada por referentes de inseguridad, abandono y violencias, lo cual implica connotaciones respecto de la concepción sobre los sujetos que los habitan o habitaron, más aún si se trata de jóvenes desde la perspectiva del surgimiento de pandillas en la ciudad y de la estigmatización delincuencial sobre el sujeto juvenil. Referentes como delincuente, ñero, gamín o rata constituyen los lenguajes por medio de los cuales son referidos por otros, pero también los que utilizan para autodenominarse en ciertas ocasiones. Estos a su vez reflejan ejercicios de exclusión y vulneración.

Es importante señalar que ambos barrios tienen una fuerte carga simbólica en la ciudad, por constituirse como referentes de expendio de sustancias psicoactivas del centro bogotano, principalmente a finales de la década de los ochenta del siglo xx. El barrio Santa Inés fue destruido; la razón más fuerte para su demolición fue que allí se ubicaba la zona conocida como "El Cartucho" ${ }^{7}$, un espacio temido en la ciudad e incluso en el país con relación a violencias y tráfico de psicoactivos. No obstante, en la actualidad algunos habitantes de Bogotá lo recuerdan como un lugar de violencia, muerte y miseria; tras varios años de su arrasamiento pervive en las memorias de quienes lo habitaron y ha trascendido las generaciones de algunas familias hasta incluso llegar a ser recordado cotidianamente por jóvenes que viven en el sector. Así, mientras para los transeúntes el parque Tercer Milenio pasa desapercibido o es un lugar poco frecuentado, vecinos y habitantes de la zona recuerdan El Cartucho, y algunos habitan el San Bernardo, barrio contiguo, el cual es nombrado y conocido por muchos jóvenes como El Samber. Llamarlo de esta forma tiene la especificidad de referirse a la zona de expendio de psicoactivos, carácter que le atribuye la carga simbólica y cultural a lo que se conoce como "olla"

En ambos barrios, el deterioro en la infraestructura es uno de los elementos a partir de los cuales se ha hecho más evidente la transformación de las dinámicas y los cambios en el uso de lo público, tales como el consumo de sustancias psicoactivas, el ejercicio de la prostitución y en general el deterioro físico por los desechos y desagradables olores.

La investigación se llevó a cabo con seis jóvenes de edades entre 18 y 28 años que han habitado el sector durante toda su vida, residen en el barrio San Bernardo, y algunos de ellos también habitaron El Cartucho. El nivel de escolaridad está entre grados octavo y décimo. Los jóvenes partícipes del ejercicio investigativo han estado fuera del sistema educativo distrital por diferentes motivos, tales como expulsión, deserción y aburrimiento frente al modelo implantado en los colegios donde han estado vinculados, ello aunado a las dificultades familiares y del entorno

7 Nombre con el cual se refirió al sector altamente peligroso en el barrio Santa Inés del centro de la ciudad, caracterizado por haber sido el principal sitito de tráfico de sustancias psicoactivas en el país y que llegó a convertirse en el lugar de muerte más temido por los ciudadanos.

8 Espacio conocido por tráfico de sustancias ilegales, violencias y control territorial. 
en el cual habitan. Si bien cuentan con un lugar dónde vivir, ya sea la casa de algún familiar, amigo o vecino, la mayor parte de su tiempo permanecen en las calles del barrio San Bernardo.

Las condiciones sociales del mundo contemporáneo exigen una mirada sensible y experiencial sobre el espacio urbano, cada vez más habitado por las juventudes en el contexto latinoamericano, lo cual se traduce en desafío analítico y comprensivo desde la geografía humanística. En la ciudad de Bogotá, el crecimiento urbano ha traído consigo desafíos para pensar una ciudad que alberga un gran número de población desplazada de otras regiones del país por las violencias desde la década de los años cincuenta. El impacto por los desplazamientos se siente de manera contundente en el área central, específicamente en la zona de estudio, comprendida por los barrios Santa Inés y el San Bernardo.

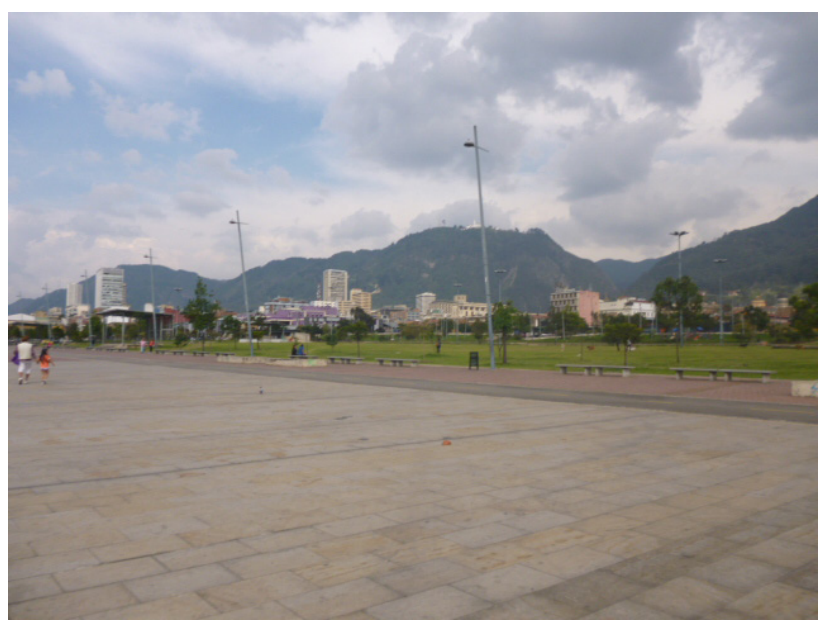

Foto 1. Panorámica costado sur del parque Tercer Milenio Fuente: Inframundos Underground

En el marco de las transformaciones de esta zona central urbana, los jóvenes que la habitan expresan las violencias que han experimentado a lo largo de su vida. Jóvenes que habitan las calles del sector, que irrumpen en la escena de lo público en un espacio signado por la violencia y el microtráfico de sustancias ilegales.

De acuerdo con Reguillo (2012), América Latina es predominantemente juvenil; por ello, es importante preguntarse por los modos de habitar de la juventud en medio de las contradicciones y desarticulaciones sociales a las cuales se enfrentan en el siglo xxı. Las condiciones desiguales en el acceso a bienes y servicios, la competitividad, la sociedad de consumo y la búsqueda de identidad que se diluye entre múltiples referentes instalan al sujeto juvenil como actor social clave para entender los procesos de espacialización en lo urbano.

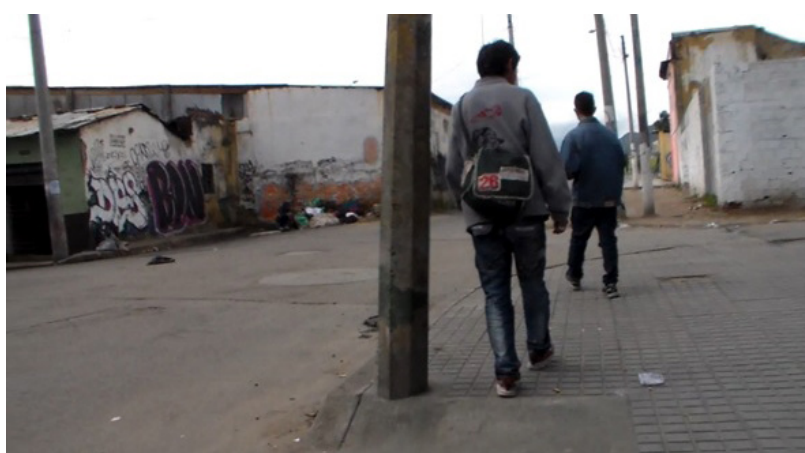

Foto 2: Del barrio San Bernardo hacia el parque Tercer Milenio Fuente: Archivo personal

La juventud, entendida más allá de la etapa del ciclo vital a la cual corresponde, da cuenta de la construcción de diversas subjetividades. La pluralidad de las formas de ser joven hoy está atravesada por las transformaciones de la subjetividad, en el marco de un mundo cada vez más globalizado política, cultural y económicamente y en el que coexisten de manera conflictiva, diferentes proyectos de sociedad. (Reguillo, 2012).

Desde la sociología se reconoce la existencia de la juventud (Bourdieu, 1990), y aunque parece un marco clasificado de manera puntual, la ambigüedad tiende a incluir en una gran heterogeneidad a la diversidad de grupos juveniles, sobre todo de sujetos que desde sus distintas posiciones y contextos asumen el mundo. Según señala Reguillo (2012), a partir de su vasta experiencia de campo en los territorios juveniles, la literatura sociológica reciente se propone superar la consideración de juventud como categorización por edad, incluyendo en los análisis la diferenciación social y cultural, para entender que su devenir depende en buena medida de las posibilidades que se encuentran en el espacio habitado.

Abordar el asunto de las juventudes supone además reconocer las relaciones sociales históricamente situadas y representadas, que constituyen diferencias inmersas en redes y relaciones de poder, que se configuran por grupo etario, por género y a nivel institucional, tales como adulto-joven, hombre-mujer, profesor-estudiante.

Bajo este marco en el cual habitan las juventudes, se propone vislumbrar la articulación entre el habitar y la experiencia juvenil en el proceso de espacialización, para contribuir a formar una perspectiva crítica de concebir la producción espacial desde las juventudes callejeras en el escenario urbano. Según Lefebvre (1972) todo espacio en las ciudades está constituido por prácticas sociales. Se asume entonces que los sujetos crean su propio espacio desde el habitar y la experiencia espacial. Para las juventudes callejeras este se constituye en el centro de su vida, permanecer en la calle con otros -en sus palabras, "parchar"- es lo que atribuye sentido a su existencia y se concretiza en su ser. 


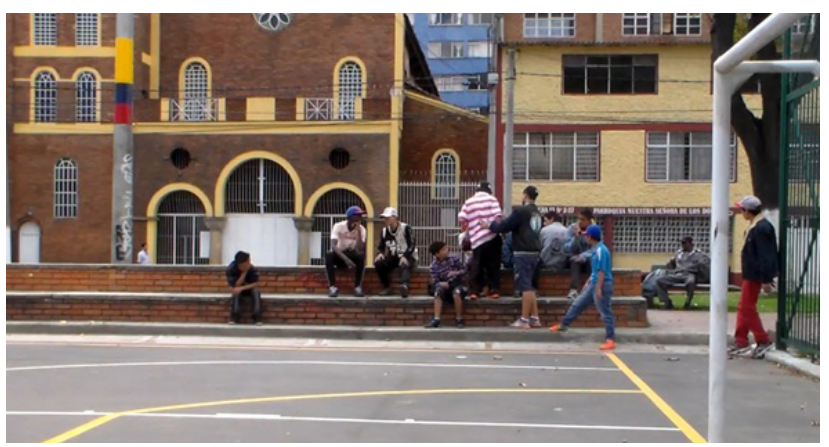

Foto 3: Parchando en el parque del San Bernardo

Fuente: Inframundos Underground

"Parchar" en la esquina, en el andén, en el parque, es una de las prácticas que cobra más relevancia para los jóvenes; su significado tiene como base permanecer en un espacio, sentirlo, vivirlo, ser de este y para este, a su vez hacerlo, darle sentido. Las calles del San Bernardo y los recuerdos del Cartucho se llevan en la piel, permiten inventar el habitar juvenil desde este contexto en la ciudad, "una ciudad trashumante o metafórica que se insinúa en el texto de la ciudad planificada y legible" (De Certeau, 1979, p. 105).

En el contexto de indagación ser joven tiene especial connotación, así como la producción y reproducción de estereotipos que alimentan referentes delincuenciales y legitiman el estigma de violencia, el cual se traslapa con la búsqueda de identidad y sentido. Para los jóvenes, sobrevivir en la calle implica apropiarse de saberes y estereotipos, así como jugar con estos estratégicamente, mientras hay que moverse con cuidado y argucia.

En medio de la heterogeneidad que configura lo juvenil, se propone mirar a los jóvenes como el lugar en el cual se anuncian las transformaciones culturales, para entrar a mundos caracterizados por la vivencia emocional y estética, más que por la racional y planificada; donde los cuerpos son vías que permiten la experimentación y el conocimiento. Una cultura fragmentada en lo urbano que responde a otras formas de trazar la caligrafía y cartografía de la ciudad desde el habitar la calle.

Las crisis económicas y políticas, así como las que enfrentan la familia y la escuela; las violencias urbanas y el deterioro ambiental han generalizado la inseguridad social y económica y a su vez han incrementado la inseguridad ciudadana. Frente a la búsqueda de progreso y democracia emergen las condiciones de inequidad y complejidad urbanas que propician la incertidumbre, las pocas esperanzas puestas en el futuro y el impulso de vivir el día a día intensamente. El debilitamiento de los escenarios de integración educativos y laborales alimenta el conformismo y la desesperanza, sobre todo en los sujetos jóvenes que se encuentran en un momento de su vida en el cual, si bien hay expectativas, también se presentan muchas exigencias para asumir modelos de vida establecidos en el ideal ciudadano, como los concebidos y aceptados por los adultos.
Rastrear lo juvenil desde movimientos alternativos, colectivos juveniles, estrategias organizativas, movimientos artísticos como el hip hop, la calle, el barrio, es uno de los retos que enfrentan los estudios socio-espaciales, de manera que se logre la problematización sobre espacios como la calle que han sido concebidos como opuestos a los espacios tradicionales de socialización (escuela y familia) y no como escenarios de participación política donde se configura el sujeto y crea desde sus prácticas, formas de subjetivación. Gracias a las reconceptualizaciones de lo político, este se constituye en una esfera que se materializa en las prácticas cotidianas del día a día de los jóvenes, para esta investigación en el habitar la calle, desde el cual se construye su experiencia juvenil y se produce la espacialización.

De acuerdo a lo anterior, cobra importancia preguntarse por las formas de ver el mundo y habitar la ciudad desde lo juvenil.

Los jóvenes latinoamericanos, sean argentinos, colombianos, salvadoreños o mexicanos, los jóvenes sin adjetivos, son un importante espejo que permite analizar hacia donde se mueve una sociedad; y el protagonismo que han adquirido en la agenda pública durante los últimos veinte años expresa de múltiples maneras el profundo malestar que nos habita (Reguillo, 2012, p. 12).

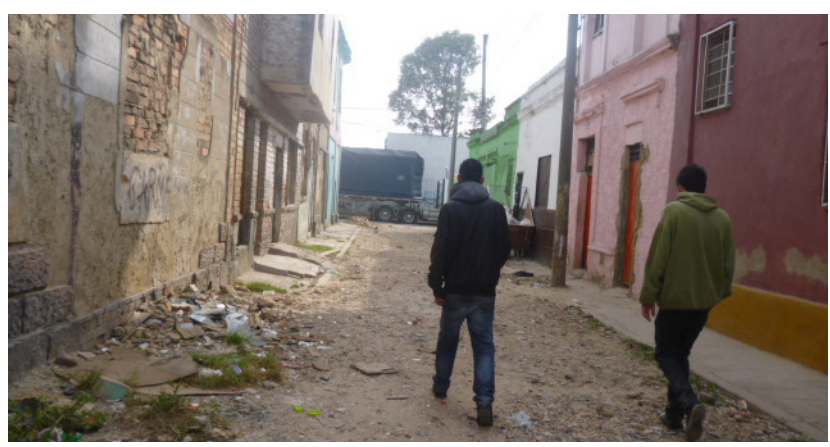

Foto 4: Caminar por las calles de San Bernardo Fuente: Archivo personal

\section{El habitar juvenil}

Se entiende el habitar como forma de ser en el mundo. Yory (1998), desde los planteamientos de Heidegger, sostiene que el ser está íntimamente ligado al habitar "yo soy, quiere decir habito". Para Heidegger ser hombre significa ser habitante, así la denominación designa la manera de ser de este como ser en el mundo. Si bien se parte del ser ahí, arrojado que es la nada, el Dasein ${ }^{9}$ de Heidegger, se toma como referente el giro que hace el autor donde el ser mismo sale a la presencia y lo importante ya no va a ser la existencia sino el sentido del ser.

9 Según Heidegger se refiere al ser ahí arrojado, en su manera más pragmática. 
En esta investigación el cuerpo es muy importante para la comprensión del espacio callejero, así como para develar la configuración de subjetividades a partir del performance materializado en la corporalidad de los jóvenes; en este sentido, a través del cuerpo el ser tiene lugar y efectivamente ocurre. Una vez sucede la ocurrencia, se devela como acto que tiene lugar, se entiende el cuerpo como la vía de ocurrencia que le da la posibilidad al ser de tener un lugar. Siguiendo a Yory (1998), Heidegger llamó a este acto, el más fundamental de todos, "ereignis" palabra que significa 'suceso' o 'evento' y que vincula con la raíz alemana "eigen", que alude a lo propio o a lo apropiado. De aquí resulta el acto de mutua apropiación entre el ser y el cuerpo en un acto de apropiación originaria. Lo propio del ser humano en cuanto ser venido a la presencia es espaciar, es decir abrir el espacio.

Espaciar como la práctica que posee un sentido para los jóvenes y produce el espacio desde sus cuerpos, desde su existencia, su permanencia, su apropiación y sus acciones. Dicha apertura no sucede de cualquier forma, tiene lugar por medio del encuentro y la apropiación del ser con la situación que lo determina como ser en el mundo lanzado, expuesto o existente.

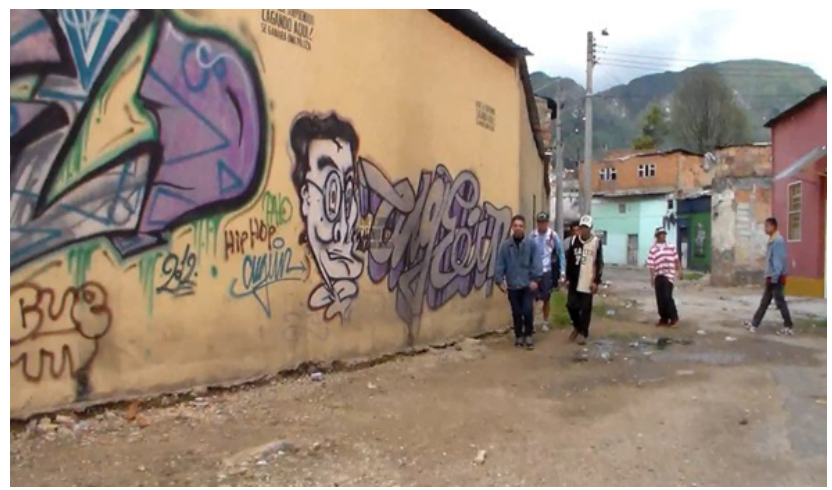

Foto 5: Una tarde en el barrio San Bernardo

Fuente: Archivo personal

En la calle los jóvenes se encuentran a sí mismos, por medio de sus cuerpos situados en ella, parte de ella, espaciando un lugar, la mayoría de las ocasiones luchándolo. El encuentro define en sí mismo la particular forma de estar en la que el propio ser se encuentra. Encuentro que al constituirse en co-apropiación permite al ser humano saberse cuerpo en su existencia. Según Heidegger hay dos forma de encontrarse: la primera es la de "antemano" que corresponde al ser ahí (Dasein); la segunda es la de salir al encuentro. Encontrarse es ser encuentro como acto que tiene lugar.

Si la espaciación es exclusiva del ser humano, dado que define su particular forma de ser en cuanto ser en el mundo, en cuanto existente como una habitación; dicha espaciación está impulsada por el sentido del ser mismo, el sentido del ser joven, del ser joven en la calle, de encontrarse ahí, de ser ahí y desde ahí. La apertura al encuentro al definirse como apropiación determina la "tonalidad efectiva" de la habitación y da cuenta de la forma afectiva del ser. La habitación como naturaleza del espaciar del ser. El ser no solo tiene un ahí sino una particular forma de venir a la presencia en mostración como existente de la propia habitación. La habitación para la investigación se encarna en los cuerpos que habitan las calles, cuerpos juveniles, marcados por la moda, la exclusión, la pesada categoría juventud y el estigma social de desocupado, delincuente y potencialmente peligroso.

La habitación anuncia la forma del espaciar, un espaciar que se produce en la calle; se habita espaciando

... gracias a que la habitación es la forma de ser del hombre en el mundo en tanto existente, el propio ser se descubre (des-encubre) a sí mismo como un ser ya enfundado en ella: "forma afectiva" de su venida-de-si-a-la-presencia como existente (Yory, 1998, p. 50).

Para los jóvenes los afectos se constituyen en tramas identitarias que se mueven entre afectos por la calle, entre alegrías, arrepentimientos, reflexiones y rabias.

El lugar será siempre de encuentro de lo que se viene a la presencia que se entiende como la ocurrente presencia. Siguiendo las afirmaciones de Yory (1998), el hecho de ser lanzado (Dasein) determina la situación como un lugar en sí mismo, que siendo propio del ser humano define también la forma humana. Situación que como una habitación exige la comprensión de la tonalidad afectiva de aquello que Tuan llamó "Topo philia”. Es decir, aquella que permite revelar la experiencia única, íntima, profundamente intrincada entre los jóvenes y el lugar que habitan, en este caso las calles. La apropiación, la relación que se constituye en un lazo fuerte, que los inspira a estar, a escribir, a expresar y a luchar, pero sobre todo que les permite ser.

\section{La experiencia en la calle}

En la investigación, la experiencia juvenil está ligada a la calle, y todo lo que ello implica: sentimientos, emociones, vivencias, relatos, recuerdos y sentido. Para comprender su configuración se hace necesario pensar tanto el "ser" como el "estar" de los jóvenes en el espacio callejero, de manera que es fundamental recurrir a los planteamientos filosóficos de Heidegger para entender las elaboraciones de Tuan sobre conceptos como la topofilia, entendida como "el conjunto de relaciones afectivas y de emociones positivas que el ser humano mantiene por un determinado lugar" (Yory, 1998, p. 51). 
Ahora bien, si se entiende la topofilia como ese conjunto de relaciones que ligan a las personas a un lugar, este es un concepto útil para comprender la forma en que se unen la calle y los jóvenes, de manera que permite conceptualizar al sujeto joven callejero como habitante en un lugar; el lugar entendido como el ámbito de convergencia del "ser" y del “estar", en el cual por un lado está el ser ahí, presente y está el ahí del ser que va más allá de su presencia, tiene que ver con su permanencia, con el sentido de permanecer ahí. En el sentido del ser en el lugar es posible hallar la dimensión afectiva y emotiva que alude a la topofilia, dado que se ejerce a través de la acción y la preservación. Esta implica el involucramiento del sujeto con el entorno y su compromiso con el mismo, así es posible acercarse a cultivar lo que se traduce en el arte de habitar.

Pero la topofilia tiene otro elemento: aquel que hace referencia a revitalizar la relación de los habitantes con el entorno y con el mundo, la cual solo es posible desde el acto mismo del habitar y el reconocimiento del profundo sentido del habitar. En palabras de Tuan, habitar vincula la afectividad (philos) entre la persona y el lugar (topos), entendido este como espacio habitado; será planteada como condición de posibilidad del habitar mismo.

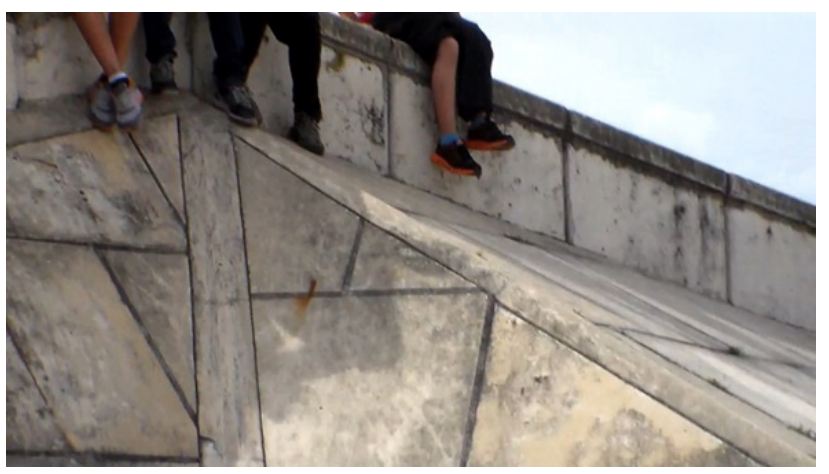

Foto 6: Habitar entre los recuerdos de El Cartucho Fuente: Archivo personal

Para Yory (1998) los diseñadores, constructores y urbanistas, son considerados "filósofos del espacio" dado que, desde su quehacer profesional han logrado teorizar sobre el espacio urbano; se puede decir que el habitar de los jóvenes en el espacio callejero los hace "filósofos de la calle" pues a partir de su experiencia directa y arraigada en el espacio han vinculado pensamiento y acción desde las reflexiones sobre su habitar, es decir sobre su ser y estar en el lugar. En este sentido la manera de "pensar" el lugar está intrínsecamente conectada con la forma de "hacerlo" y por ende en relación con la forma de concebirlo y relacionarse con él.

El "hacer" de los jóvenes en la calle se entiende a partir de los planteamientos de Yory (1998) desde su significado en Grecia: poíein, que refiere a lo "poético". En el habitar "poético" es donde se encuentran lo filosófico con Heidegger y lo geográfico con Tuan, de manera que el habitar va a propiciar la convergencia de las dos disciplinas. De acuerdo a ello es posible entender la acepción de "filósofos del espacio" y en consecuencia de cómo los jóvenes pueden presentarse como "filósofos de la calle". El espacio y todo lo que este implica (desde la producción espacial), y el sentido del ser en el mismo están profundamente ligados, y su comprensión solo será posible reconociendo dicha relación.

La calle será entonces el estado situacional donde los jóvenes se despliegan en sí mismos, donde pueden ser ellos, y en su despliegue se constituirá el hecho de fundar no como seres sobre el espacio sino como ellos mismos des-encubiertos en la acción del espaciar.

Los jóvenes en su ser se abren espacio y fundan su propia posibilidad en este. El reconocimiento de los jóvenes, de su mismo "ser" en la calle va a provocar que se encuentren a sí mismos; así dicho encuentro estará en lo afectivo, es decir en la filia (philia) y el lugar no será simplemente en el que "ocurre" el acto mismo, sino que va a ser la fundación del propio joven en su "ocurrencia", es decir tiene lugar y aparece, por tanto no es utópico.

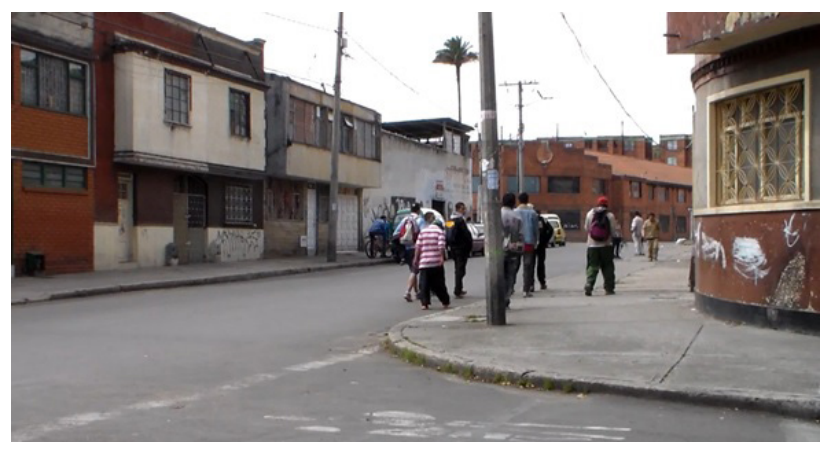

Foto 7: El estar en la calle

Fuente: Archivo personal

No es que el ser y el estar de los jóvenes se encuentre sino que el lugar (la calle) va a ser el encuentro mismo por medio del reconocimiento y apropiación. El habitar de los jóvenes no va a ser la acción del ser ahí (dasein), sino la propia acción en la que el joven se realiza.

Si para Tuan, se construye para habitar, para nosotros siguiendo al filósofo de ser y tiempo, la construcción será posible solo porque se habita, pues es precisamente la habitación la forma de ser del hombre en tanto ser en el mundo (Yory, 1998, p. 59).

Si la forma de aparecer del ser es un acto, ocurre como experiencia por medio del ser ahí, es decir el que hace saber que tiene lugar, bajo la forma del habitar la cual entonces describe su ser en el mundo, el ser de los jóvenes en la calle. 


\section{El tercer espacio en el Barrio San Bernardo desde la imaginación geográfica}

Las relaciones entre espacialidad, sociedad e historia articuladas integralmente en una problemática urbana se constituyen en las bases de la conceptualización que hace uno de los urbanistas más destacados del siglo xx, Henri Lefebvre. Este no solo invita al análisis a partir de la interrelación espacio-sociedad-historia, sino que además Ilama a la conceptualización de la producción espacial a partir de los procesos concretos, locales y barriales de la vida cotidiana.

Siguiendo el argumento más sólido de Lefebvre, todas las relaciones sociales, ya sea relativas a la clase, la familia, la comunidad, el mercado o el poder estatal, permanecen abstractas e infundadas hasta no ser expresamente espacializadas, es decir, convertidas en relaciones espaciales materiales y simbólicas (Soja, 2008, p. 38).

En la cotidianidad de las calles recorridas con los jóvenes se expresan las tensiones y contradicciones que según Lefebvre emergen de las diferentes escalas espaciales; en este sentido forman parte del proceso que describió como producción social del espacio social. De acuerdo con Soja (2008), para Lefebvre la problemática urbana emerge al observar las interacciones micro-y macro-geográficas "desde arriba" que describen la generalidad, mientras que al ser vistas "desde abajo" se sitúan en prácticas espacializadas, localizadas, es decir, concretamente en la vida cotidiana.

El sujeto juvenil callejero se concibe como particularmente espacial en la implicación de su relación compleja con el entorno. Las acciones, las percepciones y los pensamientos de los sujetos modelan el espacio que se habita, y los lugares producidos socialmente a su vez modelan las prácticas y pensamientos de los habitantes. "Si utilizamos términos familiares a la teoría social, podemos decir que la espacialidad humana es el producto del agenciamiento humano y de la estructuración ambiental o contextual" (Soja, 2008, p. 34); el agenciamiento de los jóvenes callejeros se reconoce en el marco del contexto de investigación con la profundidad que permite develar la complejidad del entramado social que se entreteje en la cotidianidad, así sus prácticas son leídas en contexto y a profundidad de manera que sobrepasan el estigma delincuencial y violento atribuido a los jóvenes.

Entender que los jóvenes forman parte de lo social, que no están fuera "que sus formas de adscripción identitaria, sus representaciones, sus anhelos, sus sueños, sus cuerpos se construyen y se configuran en el contacto con una sociedad de la que también forman parte" (Reguillo, 2012, p. 113) es una postura que cada vez toma más fuerza y sentido para quienes se asumen como apasionados del estudio de las juventudes en contextos de vulneración.
Lefebvre (1972) propone la articulación de lo físico, lo mental y lo social para analizar las realidades, las prácticas sociales, en últimas lo que sucede en el día a día, en la cotidianidad. Dicho planteamiento asume superar los productos, entendidos como la infraestructura, para situar la mirada en los procesos sociales que dan sentido a los espacios. De acuerdo a lo anterior, se hace necesario señalar lo que Soja (1997) llamó horizonte de la imaginación geográfica, a partir del cual es posible leer a profundidad la experiencia y el habitar callejero de los jóvenes para adentrarse en la configuración del tercer espacio.

En la tabla 1 se presenta el espacio vivido a partir de las experiencias de los jóvenes elaborado con sus propias palabras ${ }^{10}$, usadas de manera literal, con el fin de resaltar las connotaciones simbólicas que estos le atribuyen al lenguaje y la forma como se refleja en la producción espacial. Se pretende ilustrar cómo desde sus palabras es posible leer primero, segundo y tercer espacios.
10 Las palabras que se utilizan son las más recurrentes expresadas por los jóvenes durante el proceso investigativo y cada una tiene un significado relevante para ellos. 


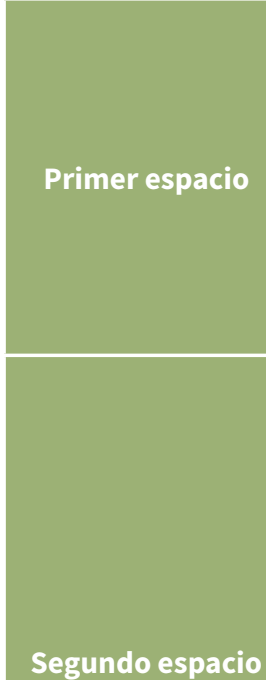

Tinto: Indica la zona de las funerarias en el barrio San Bernardo, con esta palabra aluden a que a allí se dirigen a tomar tinto gratis.

Quieto: Expresión utilizada para referir un atraco.

Tombos: Es la forma como nombran a los agentes de la policía.

Demolición: Señala que, tal como sucedió en El Cartucho, algunas casas del barrio San Bernardo fueron demolidas.

Visages: Son diferentes episodios, tales como requisas y atracos; también se utiliza para señalar sensaciones de peligro, miedo y alerta.

Expresión: Palabra que utilizan para dar relevancia a una de las prácticas más importantes, expresar sus sentimientos por medio de letras de hip hop en el sistema de transporte masivo.

Raqueta: Indica la requisa por parte de agentes de policía.

Gomelos: Utilizada para nombrar a jóvenes de barrios con características distintas a las del sector que ellos habitan.

Devotas: Se refieren a la devoción de las personas vinculadas a redes delincuenciales que rezan en la iglesia del barrio San Bernardo.

Chukyando: Indica las relaciones afectivas pasajeras y/o sin compromiso que establecen con algunas jóvenes.

Socitos: Indica los lazos de amistad callejeros

Relajaos: Usada para nombrar una sensación de tranquilidad asociada a la permanencia en un espacio.

Espacio sagrado: Es la forma como aluden al parque Tercer Milenio, pues sostienen que está construido sobre un cementerio.

Coja la curva: Acción de alejarse de inmediato de situaciones de violencia presenciadas para proteger la vida.

Tercer espacio

Calentura: Indica la zona de expendio de sustancias ilegales.

Almitas: Refiere a todas aquellas personas cercanas que han fallecido de manera violenta.

Gane de serio: Se utiliza para denotar una actitud que en el escenario callejero ayuda a la sobrevivencia.

Crypazo: Indica el recorrido por ciertas calles del barrio fumando un cigarrillo de cripy.

Coma callao: Se refiere a guardar silencio frente a situaciones de violencia que se han presenciado.

Tabla 1. El tercer espacio 
A continuación se presenta la cartografía construida con base en lo señalado en la tabla anterior. El título se toma de las ideas de los jóvenes, para quienes cambiar el nombre de Samber, con el cual refieren al San Bernardo, por Bersam tiene un significado importante; consideran que, así como las situaciones adversas se deben "voltear" para ver "la otra cara" o "el lado positivo", con el Samber sucede lo mismo, en este sentido, también hay que "voltearlo" por las difíciles circunstancias en las que allí han logrado sobrevivir.

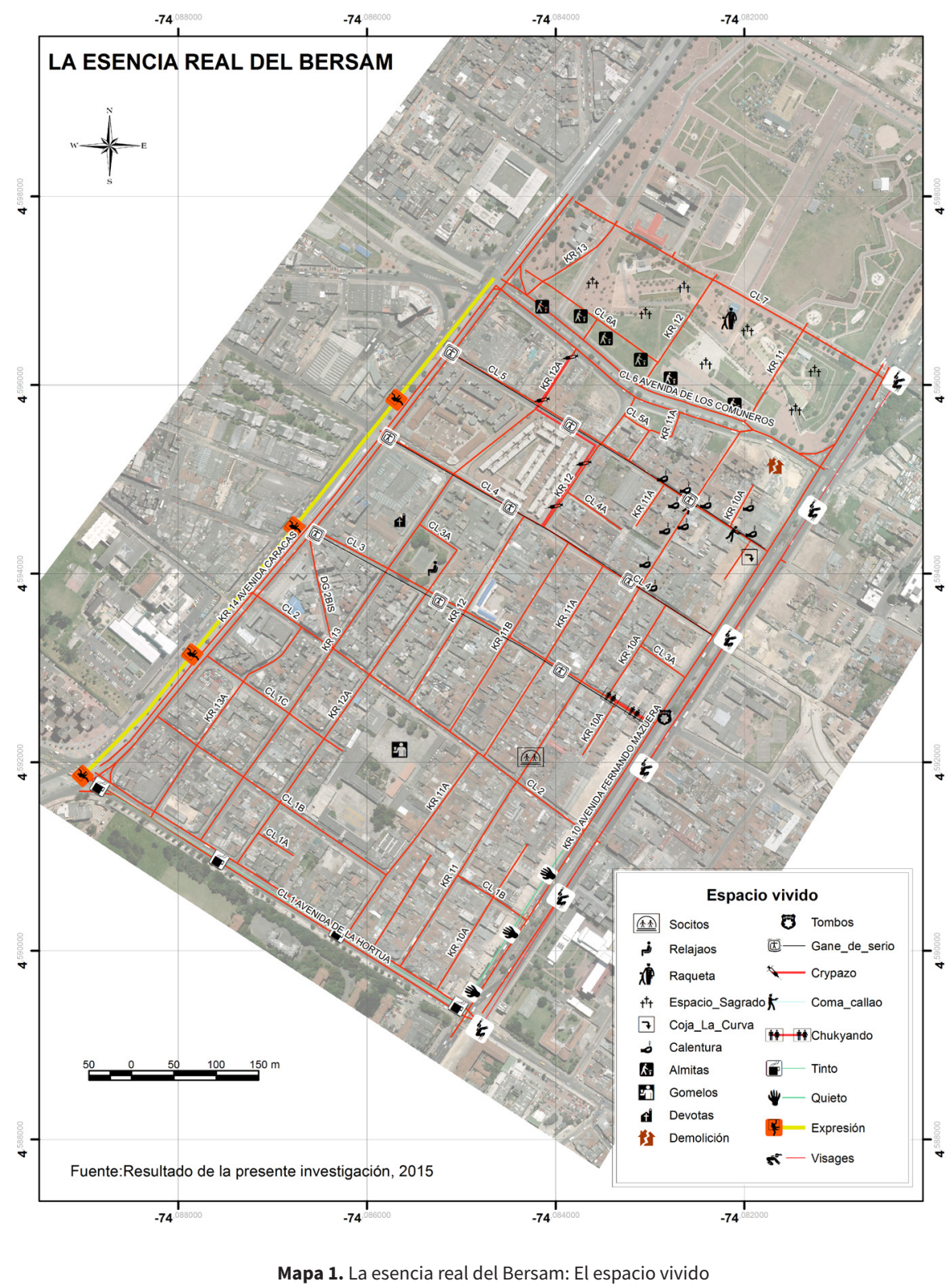


Lo anterior permite pensar la geografía en términos subjetivos y simbólicos, recogiendo el planteamiento de Soja (1997). En la investigación se acoge la propuesta de repensar el dualismo entre el primer y el segundo espacios con el propósito de lograr su ruptura y posibilitar la ampliación del pensamiento geográfico, para así adoptar la trialéctica espacial.

En la investigación se considera que la imaginación geográfica es vital para leer lo callejero, la imaginación se entiende a partir de la potencia creadora de los jóvenes que viven el espacio. En este sentido, las imágenes producidas por los jóvenes en el ejercicio permiten abordar el tercer espacio. De modo que en sus creaciones se refleja: el primer espacio que confiere importancia al mundo físico; el segundo espacio, que como espacio mental, concebido, como lo llamó Lefebvre (Soja, 1997), agrupa las representaciones del espacio, es decir, está relacionado con lo subjetivo y con la imaginación; y el tercer espacio, que incluye los otros dos, aquel espacio vivido, relacionado con la historia, equivalente en su alcance y complejidad, con el tiempo vivido.

La interrelación entre el habitar, la experiencia y el tercer espacio producidos a partir de la espacialización de los jóvenes en la calle, devela no solo la oportunidad de profundizar sobre la relación entre las juventudes y el espacio urbano sino que además presenta demandas a la imaginación geográfica en tanto nuevas formas de recrear el tercer espacio desde las voces y experiencias callejeras.

\section{Referencias bibliográficas}

Bourdieu, P. (1990). La juventud no es más que una palabra. En: Sociología y cultura. México: CNCA-Grijalbo.

De Certeau, M. (1979). La invención de lo cotidiano. 1 Artes de hacer. México: Iberoamericana.

Heidegger, M. (1951). Construir, habitar, pensar. Conferencias y artículos, España: Del Serbal. Disponible en: http://www.geoacademia.cl/ docente/mats/construir-habitar-pensar.pdf

Lefebvre, H. (1972). La revolución urbana. Madrid: Alianza.

Reguillo, R. (2012). Culturas juveniles. Formas políticas del desencanto. Buenos Aires: Siglo Veintiuno.

Soja, E. (1997). El Tercer Espacio: Ampliando el horizonte de la imaginación geográfica. En Territorios en Redefinición. Lugar y Mundo en América Latina. Sexto Encuentro de Geógrafos de América Latina. Buenos Aires. Revista Geographikos.

Soja, E. (2008). Postmetrópolis: Estudios críticos sobre las ciudades y las regiones. Madrid: Traficantes de Sueños.

Tuan, Y. (1977). Space and place. The perspective of experience. London: Arnold.

Yory, C. M. (1998). Topofilia o la dimensión poética del habitar. Bogotá: Pontificia Universidad Javeriana. 